\title{
compolitica
}

ISSN 2236-4781

\section{MESQUITA, Rafael}

Mestre em Ciência Política pela Universidade Federal de Pernambuco. Pesquisador do Núcleo de Estudos de Política Comparada e Relações Internacionais (NEPI). <rafaelmesquita_5688@hotmail.com>

Contradições identitárias do Brasil emergente: uma análise dos discursos do Estado e da imprensa

\section{RESUMO}

A identidade internacional do Brasil esteve, por muito tempo, atrelada à noção de subdesenvolvimento. A recente ascensão nacional motivou uma política externa que busca afirmar uma nova identidade internacional para o país como potência emergente, assumindo um maior protagonismo em várias frentes. O presente trabalho investigou quais tensões surgem, aos olhos dos observadores internos e externos, conforme a nova identidade tenta se sobrepor à anterior, considerando a premissa construtivista segundo a qual a formação de uma identidade é um processo intersubjetivo, cujo êxito depende de interpretação e legitimação da parte dos agentes. Para tanto, foram analisadas quais visões sobre o lugar do Brasil no mundo são mobilizadas pelo discurso oficial do Estado e pelas instituições formadoras de opinião (imprensa nacional e estrangeira) para interpretar um episódio controverso da diplomacia brasileira, representativo desse projeto identitário atual: o Acordo Nuclear assinado com o Irã em maio de 2010. Para avaliar quais visões de mundo são evocadas, o discurso oficial do Estado foi contrastado ao de dois periódicos estrangeiros e dois nacionais no período. A metodologia de análise empregada foi a Análise de Discurso Francesa.

Palavras-chaves: política externa brasileira; análise de discurso; jornalismo; identidade internaconal; países emergentes.

\section{ABSTRACT}

Brazil's international identity has been, for a long time, associated with the notion of underdevelopment. Its recent ascension has motivated a foreign policy which aims to state a new international identity for the country as an emerging power, taking on a lead role in several areas. The present study investigated which tensions arise, in the eyes of domestic and foreign observers, as the new identity tries to replace the previous one, considering the constructivist premise that identity formation is an intersubjective process, and that its outcome depends on interpretation and legitimation by the agents. In order to do so, we analyzed which visions about Brazil's place in the world are summoned by the official discourse of the Brazilian State and by the domestic and international press to interpret a controversial episode of Brazilian diplomacy, which is representative of this current identity enterprise: the Nuclear Deal signed with Iran in May 2010. To assess which world views are evoked, the official State discourse was contrasted with that of two foreign and two Brazilian publications in the same time period. The methodology for this analysis was French Discourse Analysis. Keywords: Brazilian foreign policy; discourse analysis; journalism; international identity; emerging countries. 


\section{Contradições identitárias do Brasil emergente: uma análise dos discursos do Estado e da imprensa}

\section{[Identity contradictions of emerging Brazil: an analysis of the discourses of the state and the press]}

MESQUITA, Rafael

$\mathrm{P}$ or aproximadamente um século, a principal preocupação da nação brasileira foi o desenvolvimento (CORRÊA, 2000), exercitado em diversos campos, inclusive na política externa, que buscou "traduzir necessidades internas em possibilidades externas" (LAFER, 2009, p.108). O posicionamento do Brasil no mundo esteve, consequentemente, por muito tempo modulado pela necessidade de superar o subdesenvolvimento. O crescimento econômico no plano interno e o maior protagonismo em foros externos na última década estão mudando tal cena, levando o país ao que se pode chamar de um instante de atualização identitária.

Todavia, é de se questionar se as perspectivas atuais de prosperidade e proeminência sobrepujaram a autoimagem de subdesenvolvimento e atraso. Como o exercício de novos papéis não se dá desvencilhado da autopercepção (WENDT, 1992) e considerando que a elevação de um país ao status de potência é uma questão tanto material quanto simbólica - uma vez que "status" é algo conferido e legitimado por outros -, convém analisar se as discursividades que até agora definiram as identidades brasileiras podem entrar em conflito com as mais recentes (HURRELL, 2006). 
Este artigo investiga as tensões em torno da identidade internacional do Brasil, em um momento em que o país busca abandonar o status periférico e assumir uma nova posição de potência emergente. Sendo a conquista de um assento permanente no Conselho de Segurança das Nações Unidas (CSNU) uma das principais bandeiras dessa campanha, este estudo analisa uma empreitada da Política Externa Brasileira (PEB) que visou este objetivo: o Acordo Nuclear assinado com Irã e Turquia em maio de 2010.

Inicialmente, exporemos um quadro teórico que associa premissas construtivistas, análise do discurso e estudos midiáticos. Em seguida, buscaremos definições da identidade do país, analisando para tanto o que o Brasil emergente "significa" para os diferentes agentes habilitados para defini-lo, quais sejam: os formuladores e executores da PEB (o Presidente da República e o Ministro das Relações Exteriores), e a imprensa nacional e internacional. Pronunciamentos oficiais e matérias da mídia serão analisados como forma de capturarmos as leituras de cada agente. As duas óticas serão contrastadas para vermos em que ponto a mídia compartilha das interpretações propostas pelo Executivo Federal ou as refuta, com base em alguma visão de mundo concorrente.

\section{Referencial teórico}

\subsection{Identidade: uma perspectiva construtivista}

O construtivismo é útil para compreender como ocorre uma mudança na identidade de um país devido a três características dessa abordagem: sua conceituação da identidade como um processo intersubjetivo e cognitivo; o papel que é atribuído às ideias na 
construção da realidade; sua associação entre identidade, poder, legitimidade e discurso.

Primeiramente, ao contrário das teorias neorrealista e neoliberal das Relações Internacionais, que veem identidade e interesses como atribuídos de forma exógena, o construtivismo defende que eles são endógena e intersubjetivamente gerados. A conduta de um agente para com outro não é pré-determinada pela estrutura (e.g.: anarquia conducente ao self help), mas depende de sentidos compartilhados, que são criados através de processos de interação, interpretação e aprendizado. Sob essa ótica, identidades são expectativas e entendimentos relativamente estáveis a respeito de si próprio, que se formam conforme o sujeito participa desses sentidos coletivos (WENDT, 1992).

Em segundo lugar, decorre dessa premissa que o mundo é moldado tanto por fatores materiais quanto simbólicos. Não são apenas as capacidades materiais de um Estado que ditam qual será seu comportamento, mas as crenças mantidas por ele e por seus pares. Assim, o construtivismo está em uma posição intermediária entre a visão racionalista e a visão idealista, por postular que a realidade é socialmente construída, mas lastreada por bases materiais (WENDT, 1987, 1992; ADLER, 1997).

Em terceiro lugar, as ideias que constroem a realidade também comportam relações de poder. O conhecimento compartilhado não é o somatório dos sentidos individuais, mas um conhecimento comum àqueles agentes habilitados a reconhecer e qualificar comportamento (e.g.: legítimo/ilegítimo) e que se perpetua sedimentado nas práticas sociais. Por essa razão, importa não só o poder material distribuído entre os agentes, mas também o seu 
poder simbólico ${ }^{1}$ para impor uma visão e legitimar sentidos; em outras palavras, para criar as "regras do jogo" (ADLER, 1997; HOPF, 1998).

Dessa forma, a mudança da identidade de um país, por exemplo, de periférico a emergente, não é um processo linear e cumulativo. Ele envolve uma mudança de status quo que pode acarretar conflito, não necessariamente entre Estados, porém entre visões de mundo, que batalham por legitimidade.

\subsection{O ciclo atual da identidade internacional do Brasil}

Segundo Wendt (1992), um Estado que queira modificar sua identidade no sistema internacional passará por quatro etapas: (1) quebra dos consensos sobre compromissos identitários; (2) exame crítico das ideias antigas sobre si mesmo e o Outro; (3) agir para mudar as identidades e interesses dos outros agentes engajados no sistema de interação; (4) recompensa pelo Outro e reforço positivo às novas práticas, fechando o ciclo.

Analisando a PEB, encontramos um ponto de partida desse processo nos anos 1990. A "autonomia pela participação" do governo FHC consistiu na estabilização doméstica e ingresso no regime internacional liberal com o intento de influenciá-lo, porém sem buscar a proeminência. Esse compromisso identitário esvaziou-se no final da mesma década, quando se verificou que a adesão nacional à cartilha liberal não trouxe as benesses esperadas (VIGEVANI \& CEPALUNI, 2007).

\footnotetext{
1 "O poder simbólico é um poder de construção da realidade que tende a estabelecer uma ordem gnoseológica: o sentido imediato do mundo (e, em particular, do mundo social) supõe aquilo a que Durkheim chama o conformismo lógico, que dizer, uma 'concepção homogênea de tempo, do espaço, do número, da causa, que torna possível a concordância entre as inteligências" (BOURDIEU, 2003, p. 9)
} 
Na segunda etapa do ciclo, essas ideias foram "desnaturalizadas", o que permitiu ao governo Lula mudar a ênfase da PEB, almejando um fortalecimento das relações Sul-Sul, maior equilíbrio nas relações com o Norte, multilateralismo e busca de proeminência em questões de âmbito global: era a "autonomia pela diversificação" (VIGEVANI \& CEPALUNI, 2007).

$\mathrm{Na}$ terceira etapa, o Brasil age tentando mudar percepções a seu respeito, através de gestos como o acordo com o Irã. Para que uma visão de mundo seja tida por legítima, o fator determinante é sua aceitação por vários agentes, o que torna necessária a atividade de argumentação e justificação (HURRELL, 2007). Para Fonseca Jr. (1998), a própria arena internacional é um "espaço de proposição" no qual os agentes buscam persuadir os demais. O grau de convergência dos agentes é que determinará se o feedback do Outro, na quarta etapa, será positivo ou negativo. Este processo está ilustrado na Imagem 1.

IMAGEM 1: Esquema de atualização de identidade internacional associado à evolução dos paradigmas da inserção internacional brasileira

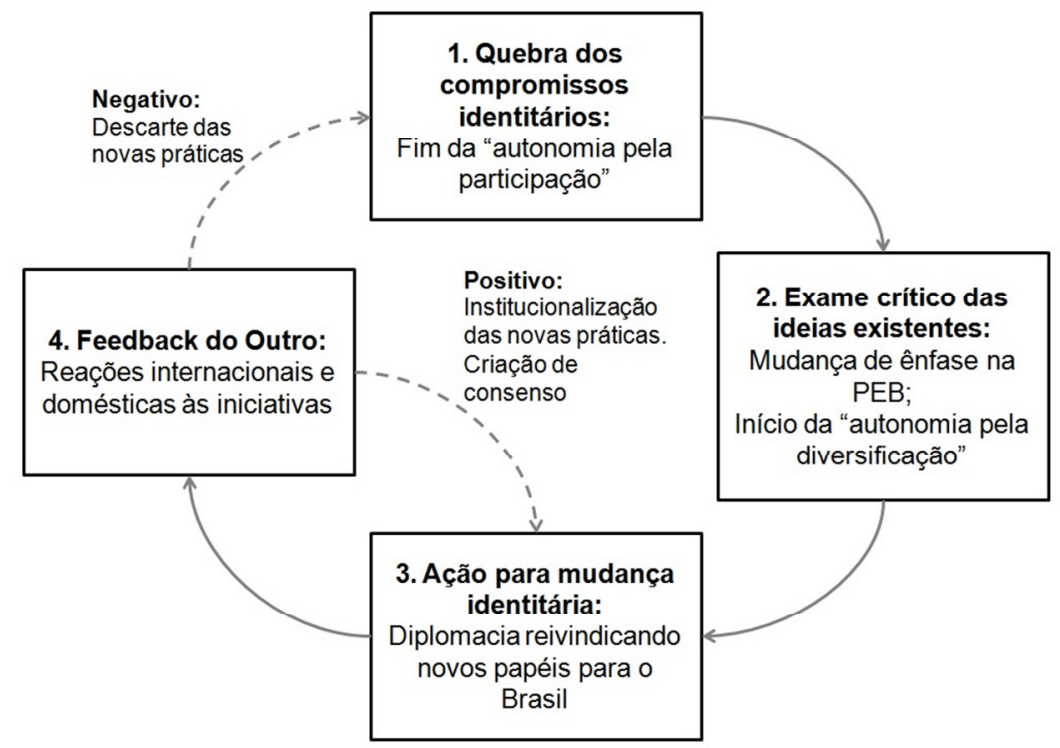

Fonte: Elaborado pelo autor baseado em Wendt (1992), Hirst \& Soares de Lima (2006) e Vigevani \& Cepaluni (2007). 


\subsection{Estado, imprensa e discurso na construção de sentidos}

Neste estudo, enfoca-se o diálogo entre dois tipos de agente: os formuladores da PEB e a mídia. Entende-se que os primeiros precisarão ir ao "espaço de proposição" internacional defender a sua compreensão sobre o lugar do Brasil no mundo, pois a ação política, diz Charaudeau (2005), exige um esforço para moldar opiniões e construir legitimidade. A imprensa tem poderes peculiares nesse âmbito, filtrando e amplificando determinadas argumentações para levá-las ao público. Para Bourdieu (2003), há um conflito entre modos de representação na sociedade, e a mídia é um campo decisivo da batalha pela opinião pública, por deter a autoridade para apresentar seletas narrativas como objetivas e autoritativas. Porto (2002) detalha que os governantes têm consciência da importância da mídia na interpretação do mundo político ao público e portanto na validação de determinada visão. Episódios controversos - como o atual - tornam essa capacidade ainda mais valiosa, pois são momentos cuja leitura depende mais da criação de enquadramentos interpretativos favoráveis do que do recurso aos fatos brutos.

Governo e mídia se valem do discurso para propor suas interpretações da realidade. Assim, neste estudo foi usada a Análise de Discurso Francesa (AD), por ser este um método que partilha das premissas ontológicas do construtivismo: o discurso como ordenador de significados que estruturam realidade social, e o imbricamento entre sujeito, linguagem e história. Em especial, são úteis à investigação os seus conceitos de interdiscursividade, que trata dos saberes compartilhados e dos "já-ditos" sobre os quais o sujeito constrói seu discurso atual, e de formação discursiva, que se refere à formação ideológica do sujeito, como esta determina o sentido dos seus enunciados e delimita quais associações textuais podem ser 
feitas e quais não (BRANDÃO, 2004; MUSSALIM, 2003; ORLANDI, 2007).

Em síntese, redefinir a identidade do país é estabilizar um sentido dentre outros concorrentes. Interessa-nos verificar como o Executivo Federal se apropria de certos saberes compartilhados (interdiscurso), orientado por sua formação discursiva, para compor uma identidade específica para o Brasil emergente, e como a mídia reage a essa imagem, quais estratégias discursivas ela emprega para legitimá-la ou não, e que fatores dentro da formação discursiva de cada veículo podem explicar suas leituras.

\section{Materiais e métodos: Seleção do corpus}

Este artigo analisa o acordo entre Brasil, Turquia e Irã assinado em maio de 2010, ao qual os EUA responderam aplicando uma quarta rodada de sanções contra Teerã. O fato gerou atritos entre Brasil e EUA, e incentivou interpretações domésticas e internacionais conflitantes. O corpus do estudo intentou capturar essa diversidade.

Primeiramente, buscou-se identificar qual seria o discurso oficial do Estado brasileiro sobre o ato. Foram analisados os discursos, artigos e entrevistas $^{2}$ do Presidente da República e do Ministro das Relações Exteriores que evocavam este episódio específico ou, de modo mais geral, as relações entre Brasil e Irã. Pronunciamentos oficiais podem ser considerados indicadores do ideal de posição do país no mundo (FONSECA JR, 1998, p.311), de modo que se tentou identificar neles quais características são atribuídas pelos interlocutores à nação com o intuito de legitimar um maior protagonismo na arena global.

2 Todos os discursos, artigos e entrevistas foram obtidos do site do MRE (www.itamaraty.gov.br) 
Esse repertório oficial foi, em seguida, contrastado com o da imprensa nacional e estrangeira. Empregaram-se dois critérios de seleção para a imprensa estrangeira. Primeiro, buscou-se um jornal dos EUA cujo leitorado fosse predominantemente norte-americano. Em seguida, buscou-se um jornal estrangeiro com leitorado geograficamente disperso. Segundo a literatura, um dos fatores que influem na atividade jornalística é o interesse nacional (ARCHETTI, 2010; NOVAIS, 2010). Este pode ser entendido como o conjunto de prioridades regulando as relações de um país com o resto do mundo, envolvendo valores compartilhados e importantes para a população (NYE, 1999, p.23, apud ARCHETTI, 2010, p.574). Assim, espera-se encontrar em um jornal norte-americano, dirigido ao público doméstico, preocupações próprias deste país. Já um periódico voltado principalmente a uma audiência internacional não tem semelhante repertório a recorrer, precisando aludir a valores mais amplos e compartilhados pelo leitorado em todo o mundo, oferecendo, portanto, um ponto de vista menos local e mais cosmopolita. Destarte, foram escolhidos o jornal norte-americano The Wall Street Journal (1,8 milhão de leitores no mundo, 92\% nos EUA) e o britânico Financial Times (2 milhões de leitores no mundo: 23\% no Reino Unido; 35\% na Europa Central, África e Oriente Médio; 9\% na Ásia; e 33\% nos EUA e Américas)³.

Para a imprensa brasileira, foram escolhidos periódicos que, primeiramente, tivessem cobertura nacional, para garantir que suas opiniões seriam influentes em todo o país; e, em segundo lugar, que tivessem ideologias editoriais distintas, visto que o viés editorial é outra variável determinante da composição das notícias (ARCHETTI, 2010, p.580). Assim, foram escolhidos o jornal de centro-direita $O$ Estado de S. Paulo e a revista de centro-esquerda IstoÉ.

\footnotetext{
${ }^{3}$ Dados do mediakit: Average Daily Global Audience (ADGA) Certificate - April 2012 to March 2013
} 


\section{0 discurso do Executivo Federal}

Foram analisados 19 pronunciamentos do Executivo Federal que remetiam ao acordo iraniano ou à relação Brasil-Irã, sendo dez do ex-presidente Luis Inácio Lula da Silva e nove do então Ministro das Relações Exteriores Celso Amorim. Todos foram proferidos entre 2009 e 2011, em sua maioria em cerimônias e solenidades ${ }^{4}$.

Para compreender que identidade esses interlocutores advogam para o Brasil emergente, buscou-se identificar através da AD: (1) quais são as caracterizações imputadas à nação com mais frequência; (2) quais delas dialogam diretamente com a busca brasileira por maior protagonismo internacional; e (3) que estratégias os interlocutores usam para construir sentidos.

Identificou-se nos pronunciamentos um conjunto de características que Lula e Amorim atribuíam ao país. Para diferenciar características evocadas por idiossincrasias do orador ou pela força da situação enunciativa daquelas mais estáveis e representativas da visão do Estado, foram considerados apenas os atributos que ressurgiram em mais de um texto ou mencionados por ambos os interlocutores em momentos diferentes. Os enunciados com esses atributos recorrentes foram agrupados por temas, resultando em dez principais características: Autonomia; Crescimento econômico/Redução da desigualdade social; Relações Sul-Sul/Universalismo/Integração Regional; Solidariedade; Valores conciliadores; Exemplo para o mundo desenvolvido; Alternativa para o modelo liberal; Porta-voz do

\footnotetext{
4 À exceção de uma entrevista e artigo de opinião redigido pelo Ministro Celso Amorim, que foram veiculadas na mídia internacional e nacional, respectivamente.
} 
Sul Global; Reforma das instituições internacionais; e

Resistência/Ceticismo de setores domésticos.

Para os fins deste artigo, foram selecionadas, dentre as dez características, aquelas mais pertinentes ao episódio iraniano. Dado que este envolveu principalmente questões relativas à segurança, às instituições internacionais e ao rol de países que nelas detêm autoridade, concentramo-nos naqueles atributos que versam sobre política externa, high politics e a manutenção do status quo da política internacional. Abaixo, especificamos quais são eles e apontamos as estratégias mobilizadas para construção de sentidos:

1. Autonomia: A autonomia é uma bandeira sempiterna da PEB, tendo sido buscada e compreendida historicamente de formas distintas ${ }^{5}$. Na retórica de Lula e Amorim, "autonomia" significa poder conduzir uma política externa sem tutela dos grandes poderes estabelecidos. O contraste com o passado é utilizado por ambos para sinalizar que a PEB atual é qualitativamente diferente da anterior caracterizada recorrentemente pelo termo "submissão" - e rompe com paradigmas sobre as capacidades brasileiras. 0 país "aprendeu a tomar conta do seu nariz"6, desenvolveu uma "diplomacia independente, sem subserviências e respeitosa de seus vizinhos e parceiros"7, passando com isso "de uma submissão aos desígnios de uma ordem internacional alegadamente inexorável para uma inserção ativa" ${ }^{18}$, derrubando com isso "'aquela velha opinião' de que o Brasil precisa pedir licença para agir nas relações internacionais". 9

\footnotetext{
${ }^{5}$ No período Guerra Fria, a autonomia era entendida como distância de ambos os pólos do confronto; no pós-Guerra Fria, como participação da ordem internacional com o intuito de influenciá-la a partir das perspectivas nacionais (FONSECA JR, 1998)

${ }^{6}$ Lula da Silva (2010b)

${ }^{7}$ Amorim (2010b)

${ }^{8}$ Amorim (2010d)

${ }^{9}$ Amorim (2010e)
} 
2. Relações Sul-Sul/Universalismo/Integração Regional: Um dos tópicos mais recorrentes é o relacionamento brasileiro com novos parceiros comerciais (África e Oriente Médio), sua participação em blocos de países emergentes (BRICS e IBAS) e seu investimento na integração regional (Mercosul e Unasul). Essa orientação atual é exemplificada ora pelo fluxo comercial ascendente ${ }^{10}$, ora pela atenção diplomática ${ }^{11}$ e contrastada com o paradigma anterior, segundo o qual investir fora do mundo desenvolvido era "desperdício de tempo e de energia"12.

3. Porta-voz do Sul Global: Citando principalmente a postura do país em rodadas de negociações internacionais marcadas por clivagens Norte-Sul, os interlocutores alegam que o Brasil tomou atitudes para "proteger os mais pobres"13 e por isso está "em posição privilegiada para fazer ouvir a voz dos países emergentes"14.

4. Valores conciliadores: Lula e Amorim enfatizam o compromisso do país com um conjunto de valores necessários para a paz internacional. O Brasil é um dos poucos países que "pode se gabar de ter dez vizinhos e não ter tido uma guerra nos últimos $140 \operatorname{anos}^{115}$, cuja grande qualidade é seu "real e profundo desejo por paz e soluções pacíficas"16, que "aposta no entendimento que faz calar as

\footnotetext{
10 "Fizemos uma nova geografia econômica e comercial. Há 20 anos, quase $70 \%$ do comércio exterior brasileiro se voltavam para os países da OCDE. Hoje, 55\% das trocas são com o mundo em desenvolvimento. Essa diversificação foi possível graças aos avanços na integração latino-americana e ao reforço de parcerias no Oriente Médio, África e Ásia. Sem abrir mão de nossos parceiros tradicionais, fizemos das relações Sul-Sul um grande ativo de nossa política externa." (LULA DA SILVA, 2010e)

11 "[E]u terei visitado 27 países africanos em oito anos de mandato, o que é mais que todos os presidentes do Brasil [visitaram], em toda a história do Brasil" (Id., 2010a). "Fui mais vezes a Porto Príncipe do que a Londres, e estive em São Tomé e Príncipe tanto quanto em Washington." (AMORIM, 2011)

${ }^{12}$ Id. (2010e)

${ }^{13}$ Lula da Silva (2010a)

${ }^{14}$ Id. (2010d)

${ }^{15}$ Amorim (2010a)

${ }^{16}$ Id. (2010c)
} 
armas"17, e cuja própria história de miscigenação é um exemplo de tolerância. A convivência pacífica de comunidades árabes e judias em solo nacional, por exemplo, legitima a contribuição brasileira no Oriente Médio $^{18}$. Merece destaque a qualificação feita quanto aos tópicos Direitos Humanos e Não-Proliferação Nuclear - alvos de críticas em virtude da aproximação de Lula com Ahmadinejad. Amorim responde que o Brasil tem "um compromisso inabalável com a promoção dos Direitos Humanos", favorecendo, entretanto, um "tratamento sem politização ou parcialidade, em que todos ricos ou pobres, poderosos ou fracos - estejam sujeitos ao mesmo escrutínio" (AMORIM, 2010b). Já quanto ao Tratado de NãoProliferação Nuclear (TNP), este é um assunto no qual o país tem "autoridade moral", por suas iniciativas passadas e compromisso firmado na Constituição; contudo, o ministro denuncia que os detentores de ogivas deveriam se empenhar pelo desarmamento assim como o Brasil se compromete com a não-proliferação (AMORIM, 2010f). Assim, o Brasil, embora adote os valores cobrados pela comunidade internacional, aponta para a parcialidade da própria comunidade em implementá-los.

5. Reforma das instituições internacionais: Ao caracterizar o Brasil em ascensão, os representantes da PEB também precisam caracterizar o contexto no qual ele ascende. Neste caso, ele corresponde à ordem internacional liberal pós-Guerra Fria, materializada em instituições como a Organização das Nações Unidas (ONU). A necessidade de reforma na ordem internacional é um tópico constante nos discursos, que ora denunciam o quanto ela é obsoleta, ora indicam como o Brasil já tem agido para reformá-la. 0 CSNU, por exemplo, não poderia continuar "representado pelos interesses geopolíticos da Segunda Guerra Mundial" e não levar em

\footnotetext{
${ }^{17}$ Lula da Silva (2010c)

18 "Aprendemos com nossa própria história que a tolerância e a igualdade de oportunidades são fundamentais para um ambiente de concórdia e de paz." Id., Ibid.
} 
conta "todas as mudanças que aconteceram no mundo" (LULA DA SILVA, 2010f), fomentando "métodos de trabalho pouco transparentes, que permitem aos membros permanentes discutirem, a portas fechadas e pelo tempo que desejarem, assuntos que interessam a toda a Humanidade" (AMORIM, 2010b).

\section{0 discurso da imprensa}

Dos quatro periódicos escolhidos, foram selecionados para análise apenas os artigos publicados em maio de 2010, mês do acordo, e que tratassem diretamente do episódio diplomático. Ao todo, 73 artigos foram analisados. Buscou-se caracterizar (1) qual imagem é atribuída por cada periódico ao Brasil emergente, (2) quais elementos e estratégias são mobilizadas para tanto, e (3) em que medida esta imagem se aproxima ou se afasta daquela esboçada no discurso do Estado, tomando como critério as cinco características identitárias elencadas na seção anterior.

\subsection{The Wall Street Journal}

Como outros veículos do conglomerado News Corp, de Rupert Murdoch, o Wall Street Journal (WSJ) é conservador (CARR, 2009). Consequentemente, não surpreende que, de todos os jornais, o WSJ represente o Irã e o acordo por ele assinado da forma mais negativa. Ao todo, 11 artigos (três notícias, duas reportagens e seis textos de opinião) foram publicados no período estudado. 
Ahmadinejad é representado como uma ameaça, não apenas aos EUA, mas a todo o Ocidente ${ }^{19}$. o programa nuclear iraniano é citado automaticamente como um "programa de armas" (e não apenas "programa nuclear") com "ambições destrutivas" (e não "ambições nucleares" $)^{20}$. Um editorial em particular se vale da figura de um "dia do juízo" ou "acerto de contas" ("day of reckoning") entre o Irã e o Ocidente ratificado na voz de um especialista, causando efeito de tensão, insegurança e catástrofe anunciada ${ }^{21}$.

Essa tonalidade alarmista faz com que o episódio seja apresentado de forma polarizada entre EUA e Irã - o Brasil é abordado marginalmente. $\mathrm{O}$ acordo não é visto como uma solução possível ou porta para o diálogo, mas como um "triunfo fajuto da diplomacia"22, um "ardil" ("ploy") ou "truque" ("gambit") iraniano, tentado na "última hora [...] para esquivar-se de novas sanções"23.

\section{3}

Como a narrativa se dá em termos maniqueístas, o Brasil não é tratado como um mediador independente, mas um possível antagonista aos EUA, usado pela República Islâmica. Pouco caso é feito da posição do Itamaraty quanto às assimetrias do TNP, tratada como um "resmungo" ("grumble") $)^{24}$ ao invés de um protesto diplomático fundamentado. No mesmo artigo, são explorados mais pontos de divergência entre EUA, Brasil e Turquia, como o arsenal nuclear israelense, as bases americanas na Colômbia e as relações comerciais que os dois países emergentes entretêm com Teerã. De

\footnotetext{
${ }^{19}$ Um artigo denuncia que Ahmadinejad têm "emergido vitorioso de seus duelos diplomáticos com o Ocidente". "The End of Nuclear Diplomacy", Stephens, B. (2010)

20 "Get ready for a nuclear Iran", Bolton (2010) e "Iran's Nuclear Coup", The Wall Street Journal (2010a)

${ }^{21}$ Stephens, B., ibid.

${ }^{22}$ Id. Ibid.

23 "Leaders from Turkey and Brazil visit Iran". The Wall Street Journal (2010b)

24 "Iranian nuclear deal raises fear". Solomon, Coker e Lyons (2010)
} 
modo que o termo mediação dá lugar à oposição, reforçando a ideia de que quem não está a favor dos EUA está forçosamente contra.

Por fim, há uma condenação moral da aliança de Lula, materializada em uma carta aberta ao ex-presidente, publicada pelo jornal no dia seguinte ao anúncio do acordo. $O$ autor manifesta sua admiração pelo estadista, enfatizando sua trajetória como defensor dos direitos humanos e da democracia, e sua consequente decepção ao vê-lo de mãos dadas com aquele que é "a encarnação de tudo que nega direitos humanos". A sua indagação é sobre o porquê de se investir numa relação que poderia sujar a sua reputação e a do país.

\begin{abstract}
Your new friend is an exterminationist [...] Your new companheiro sent rockets and bombs to Hezbollah, those terrorists and Jew-killers. [...] America and Europe have to spend billions to protect their citizens from the hate and terror encouraged and financed by your new chum. [...] why take tea with tyranny and shame your own life story? (MCSHANE, 2010).
\end{abstract}

\title{
4.2 Financial Times
}

Tradicional periódico britânico, fundado em 1888 e há 54 anos sob o conglomerado Person, o Financial Times (FT) é publicado em mais de cem países, destina-se ao público de negócios e tomadores de decisão, sendo o líder do segmento no mercado europeu. No mês de maio, 13 artigos (11 notícias, dois de opinião) foram publicados sobre o acordo nuclear.

O regime iraniano é descrito como pouco confiável, com dirigentes "provocadores", "irritadiços" e "temperamentais"25, e violador dos direitos humanos. O retrato dos países emergentes, contudo, é mais

25 "Tehran promises exit from labyrinth". Financial Times (2010) 
amigável, reconhecendo o Brasil como uma "nação confiante"26 tentando traçar "uma rota diplomática própria"27. Em um editorial, o acordo é tratado não como uma tentativa de esquivar sanções, mas como uma iniciativa diplomática promissora que pode "provar ser uma saída do labirinto de becos sem saída" das negociações com o Irã. Ele também elenca as características dos países emergentes que os tornam mediadores confiáveis: "Ambos estão se posicionando como atores independentes construindo pontes por cima da desconfiança entre o Ocidente e [...] o mundo em desenvolvimento em geral" (FINANCIAL TIMES, 2010).

Contudo, conforme as sanções se tornam mais prováveis, o periódico se torna menos otimista e lança uma reflexão sóbria a respeito do papel dos países emergentes na política internacional. "A história sugere que poderes emergentes são geralmente fracassos diplomáticos", escreve um jornalista, citando os insucessos passados do Movimento Não-Alinhado, da Associação das Nações do Sudeste Asiático e da Liga Árabe, sendo o Tratado de Tlatelolco, inspirado pelo México, o único "raro sucesso" (GARDNER, 2010).

Conforme míngua a possibilidade de se alcançar uma solução diplomática, o FT se torna mais crítico da "tensão entre poderes estabelecidos e emergentes". Os poderes estabelecidos, como o autor define, são os países dotados dos "ornamentos do poder tradicional - mais notadamente o assento permanente no Conselho de Segurança da ONU" (DOMBEY \& WHEATLEY, 2010b). Essa é uma metáfora reveladora, por denotar que há um poder "tradicional" e por definir a posse do assento permanente através de um termo ("trappings") que sugere adereço, simbolismo e uma superioridade

\footnotetext{
${ }^{26}$ Gardner (2010)

${ }^{27}$ Dombey e Wheatley (2010a)
} 
mistificada. A crítica continua em um artigo posterior, que condena o reacionarismo dos grandes poderes.

[T]he US, France and Britain have unveiled their plans for the latest sanctions [...] with obvious satisfaction. [...] Turkey and Brazil have temporary seats on the Security Council, and it is as if the permanent members are affronted the two nations should presume to strike out on their own. The Iranian nuclear issue, you could almost hear diplomats saying, is an argument that has to be settled by the established powers. If others want to help that is fine - but they should do so by backing the west's plan rather than coming up with crackpot ideas of their own. [...] They are not being invited to craft a new international order but rather to abide by the old (western) rules. (STEPHENS, 2010).

Ao evocar, logo no título, a imagem de regras do jogo ("play by the West's rules"), o autor alude, primeiramente, ao caráter arbitrário e particular dessas normas, e, ademais, à sua obsolescência - "as velhas regras (ocidentais)". Ao afirmar que não há surpresa que o Ocidente desmereça a iniciativa turco-brasileira e tenha "óbvia satisfação" nas sanções, o autor sugere que os países poderosos sempre se comportarão em defesa do seu clube hegemônico. Esse esprit de corps é reforçado quando o jornalista fala, ao invés do Conselho de Segurança da ONU, dos "cinco permanentes" ("the permanent five"): chamando atenção não para o papel da instituição, mas dos países que efetivamente exercem poder nela, para os quais mais importante do que determinar como resolver as grandes questões securitárias do mundo é determinar quem as resolve.

\subsection{O Estado de S. Paulo}

O Estado de S. Paulo é o jornal que está há mais tempo em circulação em São Paulo, tendo celebrado seus 135 anos em 2010. Embora oficialmente livre de afiliações partidárias, é notória sua orientação de centro-direita, neoliberal em economia e conservadora em 
política. Por isso, o periódico tende a ser crítico de Lula em vários tópicos, incluso política externa. Um total de 46 artigos (33 notícias, quatro reportagens, seis textos de opinião, três entrevistas) foram publicados sobre o assunto no período.

Quando a intenção de assinar o acordo foi anunciada, o jornal publicou duas entrevistas dramáticas com dissidentes iranianos, que listam as atrocidades cometidas por Ahmadinejad. A linha de questionamento da repórter evoca o tópico de direitos humanos, provocando uma condenação moral da ação brasileira.

Repórter: O sr. crê ser moral manter relações econômicas com um país cujo regime viola os direitos humanos e oprime seu povo?

M. Amiry-Moghaddam: [...] Todo o diálogo deveria estar centrado nos direitos humanos. Como qualquer indivíduo, membros de governo e empresários privados têm a responsabilidade moral de reagir diante de crimes contra outros seres humanos. (CAVALCANTE, 2010).

O jornal sugere que a publicidade foi a principal motivação para a empreitada presidencial. A primeira página do dia do anúncio do acordo enfatiza que foi o primeiro-ministro turco, e não o presidente brasileiro, que chegou primeiro às câmeras para contar o feito. Essa ênfase é refletida na escolha dos termos. "Premiê rouba cena de Lula e afirma que país abriu mão de enriquecer urânio. [...] 0 anúncio atropelou o presidente Luiz Inácio Lula da Silva, que não mencionou a questão em seu discurso." (SIMON \& WILSON, 2010b)

Com a aprovação do acordo, há uma descrença quanto à sua eficácia diante da comunidade internacional, como se vê no título da matéria do dia seguinte: "Mundo recebe com ceticismo acordo mediado por Brasil e Turquia com Irã" (SIMON \& WILSON, 2010a). Aqui 
encontramos uma estratégia redacional para atingir um efeito universalizante: embora o número de países diretamente envolvidos na questão fosse relativamente estrito - e ainda menor o que demonstrou descrença -, o jornalista iguala os poucos países implicados e céticos ao "mundo", em um movimento generalizante que resulta em maior vulto para o pólo descrente.

Todavia, uma pequena concessão à tenacidade de Lula em um editorial ("Se o futuro não o desmentir, a tenacidade de Lula vingou" ${ }^{128}$ ) revela que o jornal não desmerece por completo o feito. 0 mesmo se observa no editorial do dia seguinte à apresentação do esboço da quarta rodada de sanções pelos EUA, em que se denuncia "a delimitação dos espaços na arena mundial"29 como motivação real da reação americana. Ainda em outra matéria sobre as assimetrias do TNP, fala-se dos EUA e Rússia como "potências da velha guarda" preocupadas em "reafirmar seu poder na geopolítica mundial e pôr países como Brasil e Turquia em seu 'devido lugar'"130.

Essa concessão, todavia, é sobrepujada pela oposição do jornal ao expresidente. Com o enrijecimento do discurso dos EUA, o Estado de S. Paulo passa a focar sua cobertura nos danos que a aventura presidencial em Teerã está causando às relações Brasil-EUA. Em um artigo intitulado "O Brasil está desperdiçando toda a boa vontade dos EUA", um analista norte-americano é citado sobre a "irritação" e "desgaste" de Washington com o evento, que poderia "prejudicar o Brasil e a Turquia nos EUA" ${ }^{11}$. Em outra reportagem de capa, a então Secretária de Estado dos EUA, Hillary Clinton, é citada extensivamente sobre "sérias divergências" com o Brasil ${ }^{32}$. No mesmo artigo, listam-se outros três pontos de discórdia (embargo a

\footnotetext{
28 "O feito de Lula em Teerã", Estado de S. Paulo (2010b)

29 "A resposta americana" Id. (2010a)

30 "Ação amplia tensão entre países sem bomba e potências", Mello (2010b)

31 " O Brasil está desperdiçando toda a boa vontade dos EUA", Mello (2010c)

32 "Hillary aponta "sérias divergências" com Brasil no caso do Irã", Id. (2010a)
} 
Cuba, crise constitucional em Honduras e o TNP), avançando a ideia de oposição ao invés de mediação, e que a política externa em curso está erodindo as relações com o nosso vizinho. Isso é confirmado ao final do mês com a publicação de uma análise intitulada "Lula desconsidera as consequências de sua diplomacia", na qual os "custos da insistência" são frisados:

Divergências não chegam a ser nocivas para as relações entre duas nações sensatas, mas desta vez o Brasil passou dos limites. [...] a diplomacia presidencial de Lula avança com ambições de fazer história, com motivações eleitorais e desprendimento das consequências que trará ao País. (MARIN \& MONTEIRO, 2010).

\subsection{IstoÉ}

O periódico nacional da Editora Três se posiciona como "a mais combativa revista semanal do país" e apresenta nítida simpatia ao governo Lula, valendo-se do episódio para exaltar o governante e condenar a administração tucana anterior, bem como os EUA. Três artigos sobre o tópico (uma notícia, uma reportagem, um artigo de opinião) foram publicados no período.

A IstoÉ é a única publicação que questiona a legitimidade dos EUA em tentar conter uma escalada armamentista no Irã. Em um editorial, é resgatando um episódio ignóbil da política externa norteamericana: o caso de tráfico de armas Irã-Contras, na década de 1980, chamado pela revista de um "escândalo" e que revelou ao mundo o "grau de promiscuidade" das relações dos EUA com aquele país. A tentativa norte-americana em tentar, agora, conter Ahmadinejad seria uma "histórica ironia!". O caráter antiamericano da revista também se vê quando, no mesmo editorial, o autor afirma que as sanções comerciais foram o "último recurso" de Obama, "antes de 
partir para a força"133. Embora tal opção não tenha sido diretamente mencionada pelo presidente norte-americano - o que lhe rendeu inclusive críticas domésticas -, na visão de mundo do editorialista o uso da força é a atitude esperada dos EUA - uma percepção característica daqueles que se consideram oprimidos pelo hegemon global $^{34}$.

Esse retrato belicoso dos EUA é usado para exaltar, por contraste, o gesto conciliador de Lula. "Quando não havia mais esperança de saída pacífica, o presidente Lula entrou no caminho." (VILLAMÉA, 2010). Habilidade, prestígio e ousadia são atribuídos à ação presidencial no

(...) xadrez das negociações internacionais até então reservadas às grandes potências. Lula era a voz dos emergentes, fazendo-se ouvir na questão mais aguda do momento para a paz mundial. O Brasil não pediu licença para entrar no jogo que está tirando o sono dos poderosos (VILLAMÉA, 2010).

O posicionamento atual do país é também espaço para tecerem-se críticas à PEB sob FHC. A voz de especialistas é mobilizada para condenar o perfil da última administração, que levou o país ao "apogeu" de uma "postura subserviente" ${ }^{135}$. Essa ideia do Brasil ocupar uma posição subalterna também está visível quando o editorialista emprega um recurso estilístico curioso, ao fazer a pergunta "Como emergentes, que até então pediam dinheiro no FMI e rastejavam comando para solucionar seus próprios conflitos, habilitavam-se a protagonizar uma solução desse tamanho? Quanta pretensão!" (MARQUES, 2010). O redator se imagina no meio de

\footnotetext{
33 "Irãs-contras, parte 2", Marques (2010)

${ }^{34}$ Hoffmann (2004) discute esse sentimento, afirmando que os "underdogs" do mundo enxergam nos EUA uma natureza imperialista em decorrência de seu expansionismo cultural, militar e político. O país seria um "bully pronto para usar todos os meios, incluindo a força, contra os que o resistissem” (p.38), uma visão compatível com a expressa pelo editorialista da IstoÉ.

${ }^{35}$ Id. Ibid.
} 
espectadores perplexos com a nova situação, divergente do status quo da política global. Nota-se que a imagem construída pelo editorialista de países como o (seu) Brasil é particularmente indigna e vergonhosa ("pediam dinheiro", "rastejavam"). o vocabulário também esclarece como ideias de submissão política e dependência econômica ("FMI") estão atreladas à sua concepção da identidade internacional do Brasil.

Em decorrência do alinhamento da revista com o governo, ela não levanta críticas ao Irã, silenciando sobre o que os próprios governantes silenciariam também, como as violações de direitos humanos. Enquanto que no tocante ao programa nuclear a revista se dispõe a rebater as críticas com a presunção de inocência, direito ao programa civil e assimetrias vis-à-vis Israel, as atrocidades que ocorrem com os dissidentes do regime não ocupam nem um parágrafo sequer, de modo a preservar incólume a atuação brasileira.

\section{Conclusões}

Os posicionamentos dos quatro periódicos em relação à visão oficial do Estado brasileiro podem ser observados na Tabela 1 ao final do artigo. Os resultados sugerem que os periódicos de direita, por serem menos receptivos aos discursos por mudança no status quo mundial, recusaram-se a legitimar o papel reivindicado pelo Brasil. O WSJ e o Estado de S. Paulo condenaram do ponto de vista moral a aproximação brasileira de Ahmadinejad ao citar as violações dos direitos humanos que teriam sido praticadas por esta liderança no país islâmico, prevendo que isso danificaria a imagem internacional do país. O mesmo é apontado por críticos de Lula, para os quais a sua amizade com os rogue regimes do mundo "manchou a boa reputação mantida até então pelo Brasil" (ALMEIDA, 2010, p.174). 
O Estado de S. Paulo divergiu do governo em quase todos os elementos, exceto na opinião sobre as instituições internacionais. Fez-se uma denúncia pontual ao reacionarismo dos EUA, porém com o tempo enfatiza-se mais os danos que a aventura do presidente em Teerã causaria às relações entre Brasília e Washington. A maior divergência é a do WSJ, que não atribui ao Brasil nenhum dos atributos que este acredita possuir, adotando, ao invés, um discurso alarmista, peremptório e maniqueísta. Esse extremismo da retórica norte-americana seria, segundo Steinberger (2005), uma reprise do enquadramento bipolar da Guerra Fria, porém em tempos de novas ameaças multipolares ${ }^{36}$.

Os periódicos que mais tinham em comum com a visão do governo brasileiro foram o FT e a IstoÉ. Registra-se uma divergência do FT quanto à diplomacia Sul-Sul, não sobre o quanto a identidade brasileira se inscreve nela, mas sobre a capacidade dos emergentes de efetuarem mudanças concretas nas relações internacionais. Já a IstoÉ não dedica muita atenção à reforma das instituições hegemônicas, em parte por concentrar apenas nos EUA as suas críticas. Também, ao deslegitimar os EUA para conter a corrida armamentista no Oriente Médio, seu discurso se avizinha do estatal, que afirma que é o perfil pacífico do Brasil que o gabarita para intervir em questões da paz mundial, mais do que as potências beligerantes. Da mesma forma, a publicação reitera a vocação do Brasil para porta-voz dos emergentes.

\footnotetext{
36 "Mas antes que se pudessem criar sistemas explicativos generalizadamente convincentes para esse novo mundo de heterogeneidades e complexidades, as bem definidas polaridades da Guerra Fria vêm sendo rapidamente restabelecidas através da nova guerra contra o Terror na qual os Estados Unidos tentam nos fazer mergulhar" (STEINBERGER, 2005, p.96).
} 
Quanto às variáveis determinantes da cobertura midiática, vemos que o "interesse nacional" parece ter se comportado como esperado no episódio. Considerando prioridades para os EUA sua segurança e a segurança de seus aliados no Oriente Médio (Israel), entende-se por que o periódico norte-americano mostrou maior hostilidade à redefinição das competências brasileiras no âmbito securitário. Já o FT, londrino, porém lido por um público internacional, compartilhava da visão brasileira. O maior distanciamento da Inglaterra do epicentro da crise, bem como a ausência, no caso do leitorado, de uma nação única dotada de interesse, pode ter levado a uma defesa apenas de valores comuns a vários povos da sociedade internacional, como a solução pacífica de conflitos - que é o que o Brasil afirma procurar.

Já no âmbito doméstico, o "interesse nacional" aparenta estar subsumido pela "ideologia editorial". Observando as argumentações empregadas pelos periódicos, vemos que cada um legitimava a ação brasileira com base em sua leitura - condicionada pela ideologia do que vinha a ser o melhor para a nação. Para o Estado de S. Paulo, trata-se da manutenção de boas relações com o hegemon global e distância de rogue regimes. Já para a IstoÉ, seria a superação do perfil submisso da política externa precedente. Conclui-se que, domesticamente, há uma permanência do leitmotiv da autonomia, porém significando coisas diferentes dentro de cada formação discursiva. Para a IstoÉ, ela implica não submeter-se à tutela dos poderes estabelecidos, ao passo que para o Estado de S. Paulo, a preocupação com boas relações entre Brasil e economias desenvolvidas ecoa a preocupação com o desenvolvimento, que seria a forma de autonomia que o Brasil mais necessita. 
TABELA 1: Características atribuídas pelo discurso oficial ao Brasil emergente e seu compartilhamento pela imprensa nacional e estrangeira ${ }^{37}$
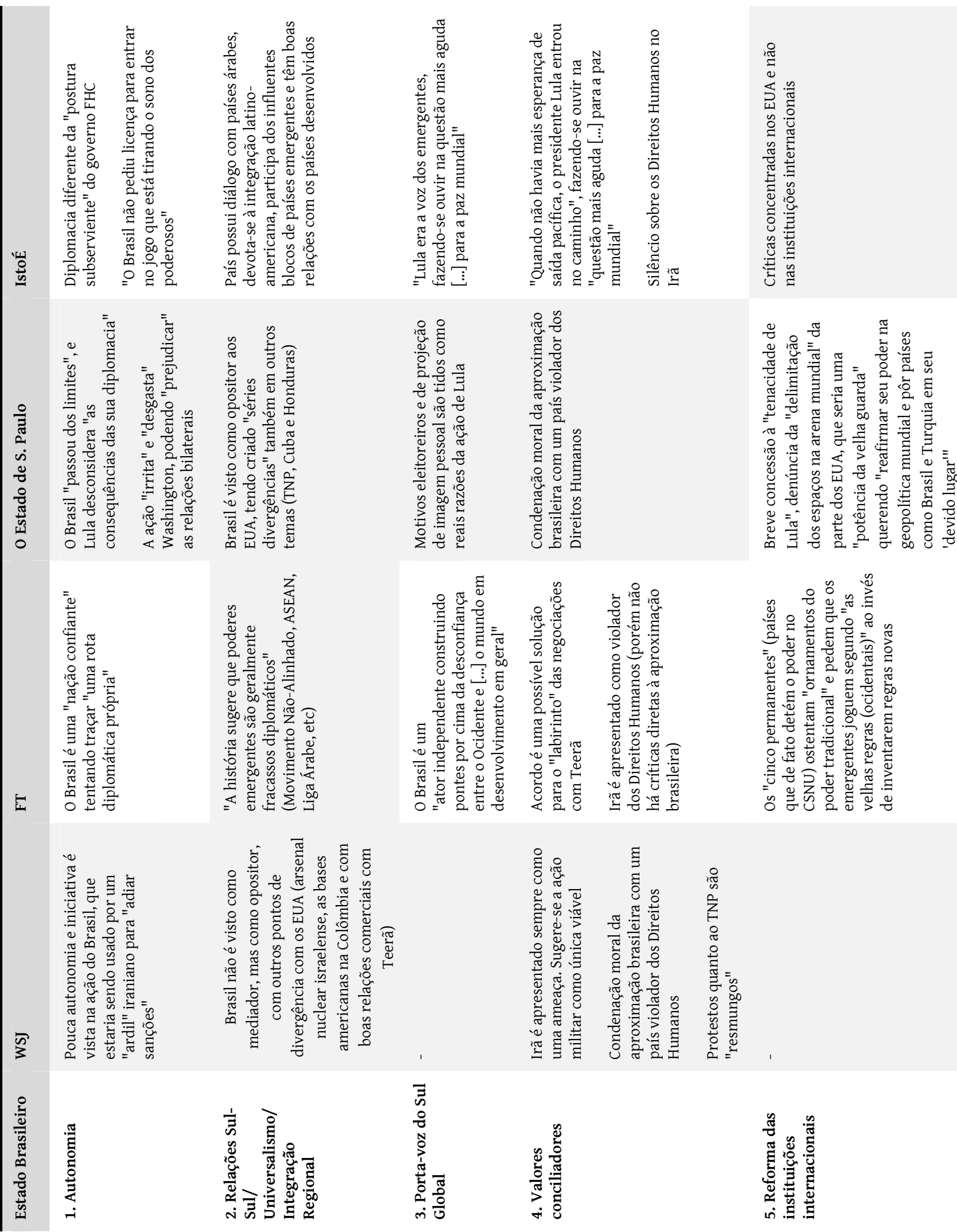

37 * Os discursos dos periódicos que se aproximam do discurso oficial quanto aos atributos do Brasil emergente estão indicados em células verdes, enquanto os divergentes, em células vermelhas. Resumos e excertos em cada célula detalham o ponto de convergência ou de afastamento. Fonte: Elaborada pelo autor. 


\section{Agradecimentos}

Uma versão anterior deste artigo foi apresentada no VII Seminário de Ciência Política e Relações Internacionais da UFPE em 24/10/2013. $O$ presente trabalho foi realizado com apoio do CNPq, Conselho Nacional de Desenvolvimento Científico e Tecnológico - Brasil. 


\section{Referências}

ADLER, Emanuel. Seizing the Middle Ground: Constructivism in World Politics. European Journal of International Relations. Vol. 3, n.3, pp. 319-363, 1997.

ALMEIDA, Paulo Roberto de. Never before seen in Brazil: Luis Inácio Lula da Silva's grand diplomacy. Rev. bras. polít. int. Vol.53, n.2, pp. 160-177, 2010.

AMORIM, Celso. Discurso do Embaixador Celso Amorim na cerimônia de transmissão do cargo de Ministro de Estado das Relações Exteriores. Brasília, 2 de janeiro de 2011. Disponível em <www.itamaraty.gov.br> . Acesso em: 15 set.2013

. The Soft-Power Power. Foreign Policy, 28 de novembro de 2010(a). Entrevista a Susan Glasser. Disponível em: <www.itamaraty.gov.br> Aceso em: 15 set. 2013

. Discurso do ministro Celso Amorim na abertura do Debate Geral 65a Sessão da Assembleia Geral das Nações Unidas. Nova York, 23 de setembro de 2010(b). Disponível em <www.itamaraty.gov.br> . Acesso em: 15 set. 2013

. Conference delivered by Minister Celso Amoriom at the Diplomatic Academy of Vienna. Viena, 21 de junho de 2010(c). Disponível em <www.itamaraty.gov.br>. Acesso em: 15 set. 2013

. Intervenção no Seminário de Alto Nível do 33 Período de Sessões da CEPAL. Brasília, 31 de maio de 2010(d). Disponível em <www.itamaraty.gov.br>. Acesso em: 15set. 2013

Discurso por ocasião do Dia do Diplomata. Brasília, 20 de abril de 2010(e). Disponível em <www.itamaraty.gov.br>. Acesso em: 15 set. 2013

Palestra do Ministro Celso Amorim na Reunião de Cúpula da organização "Global Zero: a world without nuclear weapons". Paris, 02 de fevereiro de 2010(f). Disponível em <www.itamaraty.gov.br>. Acesso em: 15 set. 2013

ARCHETTI, Cristina. Comparing international coverage of 9/11: Towards an interdisciplinary explanation of the construction of news. Journalism. Vol. 11, n. 5. pp. 567-588. Out. 2010.

BOLTON, John. Get ready for a nuclear Iran. The Wall Street Journal. Nova York, 3 maio 2010.

BOZORGMEHR, Najmeh. Iranian leaders praise Lula for role as mediator. Financial Times. Londres, 17 maio 2010.

maio 2010.

Iran warns Russia over sanctions support. Financial Times. Londres, 27

BOURDIEU, Pierre. O poder simbólico. Rio de Janeiro: Bertrand Brasil, 2003.

BRANDÃO, Helena H. Introdução à análise de discurso. 2.ed revisada. Campinas: Editora da Unicamp, 2004.

CARR, David. Under Murdoch, Tilting Rightward at The Journal. The New York Times. 13 de dezembro de 2009. Disponível em <http://www.nytimes.com/2009/12/14/business/media/14carr.html> Acesso em: 15 set. 2013. 
CAVALCANTE, Ania. "Os iranianos estão passando pelo período mais obscuro de sua história”. O Estado de S. Paulo. São Paulo, 13 maio 2010.

CHARAUDEAU, Patrick. Discurso Político. São Paulo: Contexto, 2008.

CORRÊA, Luiz F. de Seixas. Diplomacia e História: política externa e identidade nacional brasileira. Política Externa. São Paulo, vol. 9, n. 1, pp. 22-32. jun-ago 2000.

DOMBEY, D; WHEATLEY, J. Clinton attacks Turkey-Brazil deal with Tehran. Financial Times. Londres, 19 maio 2010a.

Brazil asserts role on Iran. Financial Times. Londres, 14 maio $2010 b$.

FINANCIAL TIMES. Average Daily Global Audience (ADGA) Certificate - April 2012 to March 2013. 2013. Disponível em: <www.fttoolkit.co.uk/admediakit/pdfs/adga/Adga_Certificate_April_12_to_March _13.pdf>. Acesso em: 15 set. 2013

Tehran promises exit from labyrinth. Londres, 18 maio 2010. Disponível

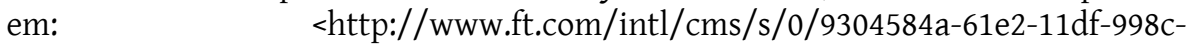
00144feab49a.html\#axzz33gm7aGb1> Acesso em: 15 set. 2013

FONSECA JR., Gelson. A legitimidade e outras questões internacionais. São Paulo: Paz e Terra, 1998.

GARDNER, David. "South-south" diplomacy put to the test. Financial Times. Londres, 19 maio 2010.

GUEDES, Fabiana. E Hillary sentiu o golpe. IstoÉ. São Paulo, 31 maio 2010. Disponível <http://www.istoe.com.br/reportagens/76750_E+HILLARY+SENTIU+O+GOLPE> Acesso em: 15 set. 2013.

GUEDES DE OLIVEIRA, M.. Interpretações da Política Externa do Governo Lula: hegemonia negociada, unilateralismo ou escapismo. Revista Política Hoje, Vol. 19, jul. 2010.

HOFFMANN, Stanley. Why they don't like us? How America has become the object of much of the planet's genuine grievances - and displaced content. In: MACCORMICK J. M., WITTKOPF E. R. (Orgs.). The Domestic Sources of American Foreign Policy: Insights and Evidence. $4^{\mathrm{a}}$ ed. Maryland: Rowman \& Littlefield Publishers, 2004. p.33-41.

HOPF, Ted. The Promise of Constructivism in International Relations Theory. International Security. Vol. 23, No. 1, pp. 171-200, Verão 1998.

HURRELL, Andrew. Hegemony, liberalism and global order: what space for wouldbe great powers? International Affairs. Vol. 82, n. 1, pp. 1-19. Jan. 2006.

On Global Order: power, values and the constitution of international society. New York: Oxford University Press, 2007.

LAFER, Celso. A Identidade Internacional do Brasil e a Política Externa Brasileira: Passado, Presente e Futuro. São Paulo: Perspectiva, 2009.

LULA DA SILVA, L. I. Discurso na cerimônia de abertura do Encontro Empresarial Brasil-Tanzânia Dar es Salaam. Tanzânia, 7 de julho de 2010(a). Disponível em: <www.itamaraty.gov.br>. Acesso em: 15 set. 2013 
Discurso na cerimônia de abertura da $10^{\circ}$ Edição Michelin Challenge Bibendum no Brasil. Rio de Janeiro, 31 de maio de 2010(b). Disponível em: <www.itamaraty.gov.br>. Acesso em: 15 set. 2013.

Discurso na sessão de abertura do $3^{\circ}$ Fórum Mundial da Aliança de Civilizações. Rio de Janeiro, 28 de maio de 2010(c). Disponível em: <www.itamaraty.gov.br>. Acesso em: 15 set. 2013.

Declaração à imprensa durante visita do Primeiro-Ministro da Turquia, Recep Tayyip Erdogan. Brasília, 27 de maio de 2010(d). Disponível em: <www.itamaraty.gov.br>. Acesso em:15 set. 2013.

Discurso na cerimônia de encerramento do IV encontro empresarial Brasil-Irã. 16 de maio de 2010(e). Disponível em: <www.itamaraty.gov.br>. Acesso em: 15 set. 2013.

Discurso durante a sessão de encerramento da XXI Cúpula do Grupo do Rio e da II Cúpula da América Latina e do Caribe (CALC) - Cancún. México, 23 de fevereiro de 2010(f). Disponível em <www.itamaraty.gov.br>. Acesso em: 15 set. 2013.

MACSHANE, Denis. Open letter to the president of Brazil. The Wall Street Journal. Nova York, 18 maio 2010. Disponível em: <http://online.wsj.com> Acesso em: 15 set. 2013.

MARQUES, C. J. Irãs-contra, parte 2. IstoÉ. São Paulo, 24 maio 2010. Disponível em: <http://www.istoe.com.br/assuntos/editorial/detalhe/75053_IRA+CONTRAS+PAR TE+2> Acesso em: 15 set. 2013.

MARIN, D. C.; MONTEIRO, T. Lula desconsidera as consequências de sua diplomacia. O Estado de S. Paulo. São Paulo, 28 maio 2010. Disponível em: <http://internacional.estadao.com.br/noticias/geral,lula-desconsidera-asconsequencias-de-sua-diplomacia-imp-,557952> Acesso em: 15 set. 2013.

MELLO, P. C. Hillary aponta "sérias divergências" com Brasil no caso do Irã. O Estado de S. Paulo. São Paulo, 28 maio 2010(a). Disponível em: <http://www.estadao.com.br> Acesso em: 15 set. 2013.

Ação amplia tensão entre países sem bomba e potências. O Estado de S.

Paulo. São Paulo, 19 maio 2010(b). Disponível em: <http://internacional.estadao.com.br/noticias/geral,acao-amplia-tensao-entrepaises-sem-bomba-e-potencias-imp-,553663> Acesso em: 15 set. 2013.

“O Brasil está desperdiçando toda a boa vontade dos EUA". O Estado de S. Paulo. São Paulo, 18 maio 2010(c). Disponível em: $<$ http://internacional.estadao.com.br/noticias/geral,o-brasil-esta-desperdicandotoda-a-boa-vontade-dos-eua-imp-,553182> Acesso em: 15 set. 2013.

NOVAIS, Rui A. News factors in international reporting. Odivelas: Media XXI, 2010

O ESTADO DE S. PAULO. A resposta americana. São Paulo, 20 de maio de 2010(a). Disponível em: <http://acervo.estadao.com.br/pagina/\#!/20100520-42583-nac-3edi-a3-not/busca/americana+resposta> Acesso em: 15 set. 2013.

O feito de Lula em Teerã. São Paulo, 18 de maio de 2010(b). Disponível em: <http://www.estadao.com.br> Acesso em: 15 set. 2013.

ORLANDI, Eni P. 2007. Análise de discurso. $7^{\mathrm{a}}$ ed. São Paulo: Pontes. 
PORTO, Mauro. Framing the world of politics: how governmental sources shape the production and the reception of TV news in Brazil, In: 23a. Conferência Anual da International Association for Media and Communication Research (IAMCR). Barcelona, 2002.

RISSE, Thomas. Let's Argue!: communicative action in world politics. International Organization. Vol. 54, n. 1, pp. 1-39. Inverno 2000.

SIMON, R.; WILSON, P. Mundo recebe com ceticismo acordo mediado por Brasil e Turquia. O Estado de S. Paulo. São Paulo, 18 maio 2010(a). Disponível em: <http://internacional.estadao.com.br/noticias/geral,mundo-recebe-comceticismo-acordo-mediado-por-brasil-e-turquia-com-ira-imp-,553170> Acesso em: 15 set. 2013.

Turquia diz que Irã aceitou acordo sobre combustível nuclear. O Estado de S. Paulo. São Paulo, 17 maio 2010(b). Disponível em: <http://acervo.estadao.com.br/pagina/\#!/20100517-42580-spo-10-int-a10not/busca/Ir\%C3\%A3+Turquia+acordo> Acesso em: 15 set. 2013.

. Lula chega ao Irã e encontra país dividido. O Estado de S. Paulo. São Paulo, 15 maio 2010(c). Disponível em: http://internacional.estadao.com.br/noticias/geral,lula-chega-ao-ira-e-encontrapais-dividido,552183> Acesso em: 15 set. 2013.

SOARES DE LIMA, M. R. e HIRST, M. Brazil as an intermediate state and regional power: action, choice and responsibilities. International Affairs, Vol. 82, pp. 21-40. 2006

SOLOMON, J.; COKER, M.; LYONS, J. Iranian nuclear deal raises fear. The Wall Street Journal. Nova York, 18 maio 2010. Disponível em: <http://online.wsj.com> Acesso em: 15 set. 2013.

STEINBERGER, M. B. Discursos Geopolíticos da Mídia: jornalismo e imaginário internacional na América Latina. São Paulo: EDUC; Fapesp; Cortez, 2005.

STEPHENS, B. The end of nuclear diplomacy. The Wall Street Journal. Nova York, 18 maio 2010. Disponível em: <http://online.wsj.com> Acesso em: 15 set. 2013.

STEPHENS, P. Rising powers do not want to play by the West's rules. Financial Times. Londres, 21 maio 2010. Disponível em: <http://www.ft.com/intl/cms/s/0/f9f1a54e-6458-11df-8cba-00144feab49a.html> Acesso em: 15 set. 2013.

THE WALL STREET JOURNAL. Iran's nuclear coup. Nova York, 18 maio 2010(a). Disponível em: <http://online.wsj.com> Acesso em: 15 set. 2013.

Leaders from Turkey and Brazil visit Iran. Nova York, 14 maio 2010(b). Disponível em: <http://online.wsj.com> Acesso em: 15 set. 2013.

VIGEVANI, Tulio; CEPALUNI, Gabriel. A política externa de Lula da Silva: a estratégia da autonomia pela diversificação. Contexto int., Rio de Janeiro, v. 29, n. 2, Dez. 2007.

VILLAMÉA, J. et al. A jogada global de Lula. IstoÉ. São Paulo, 24 maio 2010. Disponível em

http://www.istoe.com.br/reportagens/75066_A+JOGADA+GLOBAL+DE+LULA+PART E+1> Acesso em: 15 set. 2013.

WENDT, Alexander. The Agent-Structure Problem in International Relations Theory. International Organization, Vol. 41, n. 3, pp. 335-370. Verão 1987. 
Anarchy is what states make of it: the social construction of power politics. International organization. Vol. 46. n. 2, pp. 391-425. Primavera, 1992.

COMPOIITICA ASSOEIACÁO BRASILEIRA DE PESQUISADORES EM COMUNICACAOO E POLITICA

Presidente: Alessandra Aldé (UERJ)

Vice-Presidente: Luis Felipe Miguel (UnB)

Secretário Executivo: Francisco Jamil Marques (UFC)

Editora-Chefe:

Alessandra Aldé (UERJ)

Editores Executivos:

Edna Miola (UFS) e Viktor Chagas (UFF)
A Revista Compolítica é uma revista eletrônica da Associação Brasileira de

Pesquisadores em Comunicação e Política. Com periodicidade semestral, sua proposta é difundir a produção acadêmica relacionada às interfaces desses campos de estudo.

Ao citar este artigo, utilize a seguinte referência bibliográfica

MESQUITA, Rafael. Contradições identitárias do Brasil emergente: uma análise dos discursos do Estado e da imprensa. In: Revista Compolítica, n. 4, vol. 1, ed. janeiro-julho, ano 2014. Rio de Janeiro: Compolítica, 2014. 